\title{
Problems Analysis and Strategies Research on Policy Implementation of "Special Post Teachers" in Rural Areas
}

\author{
Shuang Wei $^{\mathrm{a}}$, Ying Zhang ${ }^{\mathrm{b}}$ \\ School of Education and Sports, Bohai University, Jinzhou, 121013, China \\ awsbd2000@163.com, b1071008469@qq.com
}

Keywords: rural areas; special post teachers; policy implementation; problems analysis; strategies research

\begin{abstract}
Special post teachers" policy for rural education development has injected new vitality, innovation of the rural teachers supplement mechanism, optimize the structure of rural teachers, alleviate the employment pressure of college graduates, in the education resource redistribution way, promote the balanced development of the regional education. "Special post teachers" policy although has obtained very good results, but in the security system, policy implementation, self development, teaching idea, title evaluation, evaluation methods, teaching task and pay a lot of problems still exist. To solve these problems, with reference to the literature, puts forward the corresponding strategy, further enrich the rural teacher resources allocation theory, the innovation of rural teachers' complementary mechanism, improve the effect of "teachers" policy implementation, for the rural teachers team construction provides guidance.
\end{abstract}

\section{Introduction}

"Special post teachers" is a special policy of the state to implement the education for rural obligations in the western region. The state has decided to take five years from 2006 to implement the "special job plan for teachers in rural compulsory education" in the western region. Through public recruiting college graduates to the west "two base (the implementation of the nine-year compulsory education generally available and basically eliminating illiteracy among young and middle-aged adults" counties of rural school, under the premise of without changing the teachers management, set up special positions, within the existing teachers prepare the required funds shall be borne by the central and local joint, give priority to with the central. Guide and encourage college graduates to work in the rural compulsory education, strengthen the rural compulsory education teachers team construction, innovation of the complementary mechanism of rural school teachers, gradually solve the rural school teachers' insufficient total amount and the problems such as unreasonable structure, improve the overall quality of the contingent of rural teachers, promote the balanced development of the urban and rural education. The appointment period of "special teachers" is usually three years, and the term of appointment of "special teacher" can be transferred directly to the establishment of the post office, and continue to serve the rural education cause.

Rural "Special post teachers" policy has achieved very good results, mainly reflected in the following three aspects: one is the innovation of the rural teachers supplement mechanism, embodies the principle of merit. "Special post teachers" find a source of rural teachers, to alleviate the problem of rural teachers supplement, by the central government special fund support, competitive mount guard characteristics, enhance the fairness and transparency, in teacher team construction in rural areas has a demonstration effect. Secondly, we have optimized the teachers' structure in the rural areas and have a good effect on the extension. "special post teachers" education and high professional level, improve the rural teachers' degree is low, older, meet structure face of the old and backward teaching concept. "Special teachers" Mandarin more standard, more solid knowledge of disciplines, teaching methods and diverse, pay attention to interaction with students and students quality training, active teaching atmosphere, teaching effect is good, to the rural education has brought vitality and vitality. Thirdly, the relative satisfaction of the relevant groups has eased the pressure on college graduates' employment. Students and their parents 
are the main beneficiaries of the "special teachers", and the results show that students and parents are satisfied. "special post teachers" actively cooperate with the national policies, promote the university students' employment, expand the employment of college graduates, especially for a large number of graduates in teachers colleges provide the chance of a fair competition, reduce the social hidden danger of low employment rate.

"Special post teachers" to make rural area compulsory education bursting out of the new energy, in the education resource redistribution way, vigorously promote the balanced development of the regional education, to promote the education fair, solves the problem part of college graduates employment, is a worthy of promotion policies and measures. But there have been many problems in the implementation of the "special teachers" policy, hindering the implementation of the "special teachers" policy. This paper analyzes the cause of the problem and points out the strategy of solving the problem. In theory, rich rural teachers resource allocation theory, innovation rural teachers complement mechanism; In practice, we will promote the implementation of the "special teachers" policy and provide guidance for the construction of rural teachers.

\section{Problems Analysis on Policy Implementation of "Special Post Teachers" in Rural Areas}

The implementation of the "special post teachers" in rural areas has achieved great success, but there are also many problems, which are highlighted in the following aspects:

(1) The guarantee system for "special post teachers" is incomplete and the policy implementation is not in place. "Special post teachers" policy implementation of the initial stage of the country to pay etc issued relevant documents, but the policy provisions are too general, operability is not strong, the local government may be unable to implement because of the shortage of funds, directly lead to damaged the interests of the "special post teachers". "special post teachers" service policy, after the expiry of the period of "special post teachers" development in life, if the policy is not clear, easy to cause retention and service during the period of "special post teachers" cannot work in peace, must make relevant policy, removed from the trouble back at home. A lot of the traffic and workload concerns of the "special teachers" are not mentioned at all. It is the important reason for the effect of the policy implementation of the "special post teachers" policy.

(2) The "special post teacher" lacks teaching experience and lacks self-development consciousness. Give priority to with new graduates "teachers", the lack of teaching experience and teaching skills, especially some non-normal graduates, although has obtained the teacher certification, but learn less about teaching theories and methods. The training time is shorter and the training opportunities are less, the understanding of teaching theory is not clear and the quality of teaching is not guaranteed. The cause of most of the graduates for careers in education chose the "special post teachers", but there are some graduates from the employment pressure chose the "special post teachers", the "special post teachers" as a career springboard, once you have the right opportunity will leave, self-development consciousness and level is lower, no efforts to improve the teaching level, there is no career planning, even not at ease in the teaching work, the serious influence the quality of teaching.

(3) There is a gap in the teaching concept, and the teaching effectiveness of "special post teachers" is low. Teacher's sense of teaching effectiveness refers to the subjective judgment of teachers' ability to influence students' learning behavior and academic performance. This kind of judge could affect the teacher's expectations and the guidance of the students, which affects the teacher's efficiency. Poor infrastructure, rural schools teaching the basic use of the traditional "cramming" teaching mode, the "teachers" from the university is very not adapt, because universities accept advanced teaching idea, teaching mode and teaching method. Therefore, there are obstacles in knowledge transfer, classroom atmosphere transfer, teaching interaction, teacher-student communication and after-school tutoring. Teaching idea and teaching method, make teachers have not confidence, a negative impact on the teaching effect, will affect the students' interest in learning, learning attitude and emotional activities.

(4) The job title of "special post teachers" is difficult, and the appraisal method is backward. The title is not only a kind of recognition of teachers' teaching ability and level, but also directly related 
to salary, which is one of the goals that each teacher has pursued in his career. National academic and technical titles of "special post teachers" no relevant documents, contract also does not involve the related content, in many cases are after the termination of contract and incorporated into the local personnel are allowed to assess the title. The daily management and evaluation of the post teachers shall be held by the administrative departments of the education and the administrative departments of the schools and districts. Annually over, each positioned to school the school the AD hoc post teachers' political thought work performance and comprehensive assessment, assessment of the inspection gradation, and submitted to the examination and approval by the administrative department of the county education after deposited in the archives work. This kind of appraisal is easy to implement, but the method is backward, can not reflect "the teacher" real work performance.

(5) The "special post teachers" are overweight and underpaid [2]. Rural school teachers resources is the accumulation of a long, long time, in recent years, the implementation of the "special post teachers" plan, far cannot meet the practical requirement of rural education. Because the teachers lack, many rural school teachers bear the heavy task of teaching, and the arrival of the "special post teachers", the young tend to take on more teaching tasks, the working condition of overload facing great mental and physical pressure. Although the pay treatment of "special teachers" has specific documents, it is still difficult to achieve. Default salary, plus the "teachers" problem such as low wages than writing teachers, many "special post teachers" living without protection. The quality of teaching is difficult to guarantee when both mental and physical conditions are not met.

\section{Strategies Research on Policy Implementation of "Special Post Teachers" in Rural Areas}

According to the research and analysis of the author's research and analysis on the "special post teachers", this paper puts forward the following strategies:

(1) To improve and implement relevant policies and to improve the appeal of the work of "special teachers". Specific measures include the following five aspects: first, about the salary issue, further simplify to grant program, standardized method, adjust the size, to establish salary system to carry out the accountability mechanism, prevent salary be occupy, divert, and not full specified amount to issue and other issues. Second, on the issue of the service to stay on after the expiry of the period, in advance to ensure that the "special post teachers" job and salary, as the "teachers" create conditions to remain in the local school education as a career, transfer procedures and treatment to carry out the responsibility main body [3]. Third, after the termination of service to choosing a career "special post teachers", attend graduate and civil service exam plus policy, implement re-employment as opposed to a town primary and secondary school teachers supply system, offer certain priority in employment. Fourth, pay attention to the supervision and accountability of policy implementation, as a special group, the "teachers" in remote mountain areas, distribution is more dispersed, cause, and limited ability to maintain their own rights and interests of online rights protection should be combined with online petition, clear the responsibility main body, to solve the problem to prevent multiple departments mutual shuffle phenomenon. At the same time, we will strengthen internal government oversight and accept social and media oversight. Fifth, the regional realities should be combined, and the pace and frequency of policy implementation should be taken as a whole.

(2) We will continue education to promote the development of teachers. Teachers' professional development is refers to the teachers as professionals, in a professional, professional knowledge and professional ability aspects such as process of constant development and improvement, namely by professional novice to expert teachers. Teacher development is the process of teachers' life value realization, is a teacher on the basis of fully understanding the meaning of education, enhance the spirit of pursuit, enhance the professional ethics, master the law of education, expand the subject knowledge, strengthen their professional skills and improve the level of education the teaching process. First, pay attention to the "teachers" training, training in view of the actual demand, adjust the "teachers" mentality, to enhance the "teachers" teaching profession consciousness, sets up the service of the rural education career ideals; Understanding of the fundamentals of the current education situation and the education teaching rule, and it is engaged in the education of primary 
and secondary schools teaching professional ethics accomplishment, the basic theory of education, subject teaching abilities and skills. Then, the professional development level of "special teachers" should be promoted with professional practice. Through the reflective teaching and teachers' action research, found the problem in the process of teaching, reflective teaching, improve teaching skills, from the external force to emphasize the internal mechanisms, improve the ability of professional development, to show their talent in rural school.

(3) The reform of the rural basic education is driven by the advanced teaching concept of "special post teachers". The focus and difficulty of China's education is in the countryside, and there is no modernization of education in China without the modernization of rural education. The reform and development of education in rural areas directly affects the changes of rural society and the development of [4]. As a graduation time soon "teachers", in the university accepted the advanced teaching ideas and teaching methods, therefore, to be a rural school teaching idea and teaching method reform of promoters and pioneer, countries should also strengthen the integration of existing education resources and utilization, build all-round development education environment for students. specific content of the reform include three aspects[5]: first, to "guide learning" as the carrier, the organic integration of "teaching" and "learning", achieve the unity of teaching, students' effective learning as the specific requirements of the teaching design; 2 it is, "learn to teach training promotion" teaching mode, highlights the subjectivity of students, cultivate students' autonomous learning ability and emotional attitude, strengthen the ability training, and pay attention to the mutual exchanges between students; Three is, the use of advanced teaching strategies, pay attention to the whole process of students' learning, guide students to independent development, through the students' autonomous learning and cooperative exploration, the interaction between teachers and students, the implementation of teaching and learning combined with each other and promote each other.

(4) We will improve the evaluation system for the "special post teachers" and establish a scientific assessment system. Performance appraisal is the verification and evaluation of the work, which is an important means to motivate the "teachers of the post" to work hard. Assess the performance of the teachers, further arouse the enthusiasm of the excellent teachers, and make the evaluation result not ideal teacher clear the direction of effort. To realize the equity and justice of the results of the appraisal, the appraisal system is very important, so we must improve the appraisal system, people-oriented, reflect the "teachers" humanity care, care about their work and life, ensure that the "teachers" and other teachers enjoy equal opportunities, making them more focus on their work. Through the perfect appraisal system, stimulate the "teachers" work enthusiasm, let them feel the government's emphasis on "teachers" groups and attention, prompting "teachers" love work, love the school, feel the value of work, set up the government and the image of integrity, improve the effect of policy implementation of the "work plan". Formulate scientific and reasonable evaluation index system is the precondition of the evaluation results objective notary, have to be generalization of the collected data, using the method of logic reasoning, combines the subjective and objective factors were analyzed, and the building has the gradation index system, in order to realize the comprehensive assessment of the "teachers".

(5) To arrange the teaching tasks of the "special post teachers" in a reasonable way and keep raising the salary. For "teachers" teaching task heavy and overworked, etc., should according to these teachers, professional teaching and professional direction course arrangement, reduce other subjects teaching, make the young teachers have time and energy to study teaching, in pay attention to the process of "quantity", pay more attention to "quality" rise, let the "teachers" give full play to their own professional and technical level, strive to create "the high-quality goods curriculum", make both teachers and other students benefit from it. In addition, can also according to the characteristics of the "special post teachers" lack of work experience, arrange some auxiliary other teachers' teaching work, let the "special post teachers" in the study. The wages of "special post teachers" should be issued strictly in accordance with the state regulations and not in arrears. For "special post teachers" wage income is lower than at teachers, the school can according to the state council executive meeting on the implementation of compulsory education school guidance of merit 
pay, according to the rules of establishment and salary standard, the teachers' salaries in full into the fiscal budget, on time full specified amount [6]. Adopt a pay-for-performance approach, not only make the job involvement is proportional to the income, at the same time make the "teachers" in the psychological balance, stimulate the work enthusiasm, improve work enthusiasm.

\section{Acknowledgement}

Research base special project of "the Twelfth Five-year Plan" on educational science of Liaoning province (JG15ZXY15): Research on effect evaluation and optimization mechanism for policy implementation of "Special post teachers" in rural areas; Postgraduate teaching reform project of Bohai university: Practical construction on professional skill training system for master's degree in education

\section{References}

[1] J. Z. Zhang, "Implementation of the Policy of 'Special-post Teachers' in the Rural Areas: Problems and Countermeasures," Theory and Practice of Education, vol. 32, no. 7, pp. 26-28, 2012.

[2] J. Luo, Y. Cheng, "Problems and Their Counter Measures in "Special-Post Teacher Program" in Rural Areas," Journal of Xuzhou Normal University (Educational Sciences Edition), vol. 1, no. 4, pp. 61-63, 2010.

[3] X. Ma, C. C. Shi, "Research on Implementation Countermeasures for 'Rural compulsory education stage school teachers ad hoc post plan'," Education Teaching Forum, vol. 5, no. 5, pp. 10-12, 2013.

[4] H. A. Peng, H. B. Feng, "Basic Education Reform in the Rural Areas: Plight and Countermeasures," Theory and Practice of Education, vol. 30, no. 8, pp. 25-27, 2010.

[5] Learning network, "Primary school classroom teaching reform implementation plan," http://www.cnfla.com/fangan/56258.html, 2017-4-20.

[6] S. Q. Tu, "Analysis on the problems and Countermeasures in the implementation of 'special post plan' in Jiangxi rural areas," Journal of Jiangxi Radio \& TV University, vol. 22, no. 3, pp. 88-91, 2015.

[7] F. Liu, "Research on the strategies for the development of bilingual teachers in Minority Areas," Journal of Hotan Normal College, vol. 36, no. 1, pp. 48-50, 2017.

[8] Q. F. Li, Q. L. Wu, "A survey on the survival and development of rural primary school teachers," Teaching \& Administration, vol. 33, no. 6, pp. 24-26, 2016. 